\title{
Decision-making for use of complementary and alternative therapies by pregnant women and nurse midwives during pregnancy: An exploratory qualitative study
}

\author{
Marie Hastings-Tolsma ${ }^{1 \star}$ and Deborah Vincent ${ }^{2}$ \\ ${ }^{1}$ University of Colorado Denver College of Nursing, Division of Women, Children and Family Health, USA. \\ ${ }^{2}$ University of Arizona, Tucson AZ, USA.
}

Accepted 26 April, 2013

\begin{abstract}
Millions of people use complementary and alternative medicine (CAM) therapies. Such therapies are used across a wide spectrum of health conditions, but the use is particularly notable during pregnancy. Despite the widespread use, little is known about the perceptions of patients and clinicians in deciding about use of varied therapies. This study describes pregnant women and obstetrical provider (nurse midwives) perceptions in decision-making for use of CAM therapies during pregnancy. Pregnant women and nurse midwives were interviewed in focus groups with transcribed data analyzed using content analysis. Four themes emerged from the session with pregnant women and 3 from the nurse midwives. Data underscore the need to dialogue with all pregnant women about CAM use, and to mainstream CAM in education programs. Given the paucity of evidence for safety and efficacy during pregnancy for most CAM therapies, decision-making strategies to fill those knowledge gaps are urgently needed.
\end{abstract}

Key words: Complementary therapies, alternative medicine, pharmacognosy, traditional medicine, decisionmaking, pregnancy, obstetrical providers.

\section{INTRODUCTION}

Complementary and alternative medicine (CAM) is involved in 65 to $80 \%$ of the world's health care practices (WHO, 2008). These estimates of use were also noted in developed countries where rates of use have steadily increased (Pan et al., 2012). In the U.S. alone, as many as 72 million use at least one CAM therapy each year with an estimated 425 million alternative provider visits annually at a projected cost of $\$ 27$ billion (Barnes et al., 2007; Institute of Medicine, 2005). Such therapies are used across a wide spectrum of health conditions with notable use by women (Upchurch et al., 2007) and in pregnancy (Adams et al., 2009; Gibson et al., 2001; Hepner et al., 2002; Refuerzo et al., 2005; Steel and Adams, 2012; Tsui et al., 2001), commonly to reduce pregnancy-related problems (e.g., nausea) or promote cervical ripening and the onset of labor (Hastings-Tolsma and Terada, 2009).

Many obstetrical providers recommend use of CAM therapies during pregnancy and birth (Hastings-Tolsma and Terada, 2009; Furlow et al., 2008) and there have been efforts to move use of CAM therapies into mainstream professional education in recognition of its 
common use and potential value as a treatment modality (Pan et al., 2012).Despite widespread use by patients and frequent recommendation by obstetrical providers, little is known about how pregnant women and providers feel about CAM use during pregnancy and birth, nor how they make the decision for or against use. Data which informs how patients and providers communicate their perceptions about CAM use, factors considered in decision making for use, and how differing values are considered in making a decision are needed (Ventegodt et al., 2011). Where CAM is used, patient and provider must evaluate how useful the intervention was for the intended purpose.

Though popular, little is known about the critical decisions faced by pregnant women and clinicians in deciding to use CAM therapies where little information about effectiveness and potential adverse effects often exists. Even less is known about how uncertainties between patients and clinicians are reconciled. Increased knowledge about patient and provider perceptions of CAM use has the potential to contribute to the development of decision analytic models that synthesize the available evidence for consideration of the use of health interventions and for providing a framework to establish the value of further research (Claxton, 1999). At a time when health care resources are stretched perilously thin, characterizing the perceptions about the value of CAM interventions during pregnancy and birth is vitally important in the determination of whether additional evidence is needed before recommending use in clinical practice (Claxton, 1999).

Translating evidence-based knowledge into health care practice requires consideration of individual patient and provider preferences for various outcomes. It is difficult to help patients make informed health care decisions unless factors that influence CAM use are clarified and examined in concert with factors that facilitate or hinder provider prescribing of CAM therapies. To our knowledge, this dual qualitative approach to determining provider and patient perceptions of CAM use during pregnancy has not been reported heretofore. The overall goal for eliciting these perceptions was to inform the development of a decision model for use of CAM therapies. While decision-making for CAM use by patients with chronic conditions has been explored (Caspi et al., 2004), decision-making models which consider patient and provider factors, particularly in diverse populations are urgently needed. This research has the potential to add a unique dimension to the literature that may be particularly important in developing an accurate decision making model and in guiding directions for further research.

\section{Study purpose}

The purpose of this study was to elicit information about how pregnant women and nurse midwives make decisions regarding the use of CAM therapies during pregnancy and birth. Information obtained from this exploratory study is being used to inform the development of a decision model for use of CAM therapies.

\section{METHODOLOGY}

\section{Research design}

A qualitative descriptive design was implemented in which focus groups were used to elicit data from nurse midwives and pregnant women. Focus group methodology was suited to this particular study because it allowed for relatively rapid assessment of the experiences with CAM during pregnancy by the target groups. Focus groups are useful in understanding how people think and learn about health behaviors, including herbal and other CAM therapies (Blanchard et al., 1999; Vincent et al., 2006). The method is useful in understanding issues regarding healthcare uses and in indentifying barriers to use (Halcomb et al., 2007). In this study, focus groups aided in eliciting information about decision making to use or not use CAM during pregnancy.

\section{Development of moderator's guide}

Two members of the study team (MHT and DV) developed the moderator's guide based on their previous research, clinical experience, and review of the literature. The principal investigator (MHT) provided expert clinical knowledge of herbal use in pregnancy. MHT has more than 10 years of experience in using herbal therapies during pregnancy and labor and delivery. Expertise in focus group methodology and moderation of the focus groups was provided by the co-investigator (DV), who has used focus groups in several studies.

Content validity of the moderator's guide was established by a literature review of herbal and other CAM use in pregnancy and by consensus of the research team and a consumer advisory board. Questions focused on what therapies were used by pregnant women and which CAM therapies were recommended by nurse midwives and their comfort level in discussing such therapies with pregnant women.

\section{Sample}

This purposive sample composed of two separate groups: nurse midwives and pregnant women. Nurse midwives $(n=4)$ were selfidentified as a certified nurse midwife, 18 to 65 years of age, English-speaking, a minimum of 3 years obstetrical experience and currently in clinical practice. Pregnant respondents $(n=3)$ had a lowrisk singleton pregnancy with no contraindication to vaginal birth, were 18 to 45 years of age, English-speaking and able to read and write in English. Women representing a range of ethnic backgrounds were sought.

Respondents were recruited through email announcement to providers inviting interested individuals to contact the investigators for additional information. Providers were also asked to forward the names of any interested pregnant patients. A description of the study was included in the email sent to providers for distribution to potentially interested pregnant women.

\section{Protection of human subjects}

The study was approved by the University of Colorado Multiple Institutional Review Board prior to enrollment of participants 
(protocol \#12-1433). Nurse midwives and pregnant women were provided a small monetary incentive for their time and expertise which was given at the conclusion of the focus group sessions.

\section{Data collection procedures}

Two meeting sites were selected for convenience of all respondents and dates and times were determined based on respondent schedules. Each focus group lasted approximately $90 \mathrm{~min}$ and both sessions were audio recorded. The same facilitator (DV) conducted both focus groups, which were held in a private conference room and conducted in English. A second investigator (MHT) sat in on the entire focus group sessions, taking field notes throughout. Field notes allowed for comparing the mood of each session, body language of respondents, and preliminary identification of themes. This observing investigator also operated the tape recorder and helped with focus group logistics.

Each focus group began with an explanation of the purpose of the meeting. A written consent form, including permission to audiotape, was read aloud by the moderator and reviewed and signed by each respondent.

Ground rules were explained by the moderator in each session. These included: there are no right or wrong answers, everyone's opinion is important, no one has to speak but everyone who wants to should have a chance; respondents were also asked to refrain from sharing conversations, stories, or identities of other group members with anyone outside of the group. Demographic data were collected using a brief questionnaire. Pregnant respondents were asked a variety of questions including estimated due date, current and past use of CAM therapies, and the type of obstetrical provider seen for prenatal care. Provider respondents were asked similar questions including educational background, and nature of their clinical practice experiences. Table 1 details the questions which guided the focus group sessions.

\section{Data analysis}

After each focus group session, a transcriptionist made a verbatim transcript of the audiotaped data. Both members of the research team read and approved drafts of the transcripts. Data analysis preceded using qualitative content analysis. Research team members read the transcripts looking for symbolic domains of meaning, and within domains, relational patterns and themes. The researchers inductively developed codes and met to discuss code definitions and the application of codes to all focus group transcripts. Next, code families were developed to cluster similar codes and address the research questions. The research team discussed and researched consensus on the refinement of categories and themes.

\section{RESULTS}

\section{Respondent characteristics}

Size of the focus groups varied from 3 to 4 members, with the provider group being larger. Pregnant respondents ranged in age from 21 to 40 years, most were married, either Hispanic or White, and had education levels beyond high school. All pregnant respondents were seeing nurse midwives for their for their obstetrical care and were greater than 20 weeks gestation. Nurse midwives who participated in the study were all female and the majority was married, White, and Christian. The majority was employed part-time in a public facility and all had over 20 years of clinical obstetrical experience. All nurse midwifery respondents provided prenatal and postnatal clinical care; some provided intrapartum services. Table 2 details the demographic characteristics of respondents.

\section{CAM therapy use}

\section{Pregnant women}

All pregnant respondents reported using several CAM therapies both before and during the current pregnancy (Table 3). Use covered a wide range of therapies from all five CAM categories as defined by the National Center for Complementary and Alternative Medicine (2012). These categories included natural products (herbs, vitamins, minerals), mind-body medicine (yoga, meditation, acupuncture), manipulative and body-based practices (massage), and other CAM practices (homeopathy). Of note is that some respondents admitted to being unaware of exactly what they were using but believed it likely to be efficacious, because it was recommended for use by a respected source and because it was a CAM therapy. One pregnant woman noted:

"I have a balm that is not from the United States. I do not know the name for it. It is Chinese medicine and it is similar to the balms that you breathe when you are sick. When I was a little bit sick, I used it and applied it to different pressure point. I have used that all my life, not only for pregnancy".

Another pregnant respondent noted:

"I have used acupuncture; I used it throughout my whole pregnancy, to support it. My acupuncturist prescribed herbs that I used."

She also reported not knowing exactly what the herbs were that she used, just that "they are used to sustain a pregnancy in the first trimester." Two pregnant respondents talked about ginger or limes or oranges for nausea and another pregnant respondent used "...oatmeal to shower because of itch".

\section{Nurse midwifery providers}

Nurse midwives reported using a number of CAM therapies, though most were natural products (herbs, vitamins, minerals) and other whole medicine CAM therapies such as homeopathy (cohosh). In addition, a number of CAM therapies were identified as being asked about by patients. Nurse midwifery providers expressed ambivalence about recommending use of these therapies citing unknown safety and/or efficacy. 
Table 1. Schedule of questions.

\begin{tabular}{|c|c|}
\hline Pregnant respondents & Nurse midwife respondents \\
\hline $\begin{array}{l}\text { Who did you talk to about your decision to use (or } \\
\text { not) a particular CAM therapy? }\end{array}$ & $\begin{array}{l}\text { In general, what role do you think CAM therapies play in pregnancy } \\
\text { and birth, if any. }\end{array}$ \\
\hline $\begin{array}{l}\text { Did you share with your health care provider your } \\
\text { decision to use the particular CAM therapy(ies)? } \\
\text { And, if so, what was the response you felt you } \\
\text { received (supportive/unsupportive/neutral)? }\end{array}$ & $\begin{array}{l}\text { What have been your experiences related to patients using CAM } \\
\text { therapies in pregnancy and/or birth? }\end{array}$ \\
\hline $\begin{array}{l}\text { Was your provider's response influential in your } \\
\text { decision about CAM use? }\end{array}$ & $\begin{array}{l}\text { What specifically are you aware patients use, for what reason, and } \\
\text { how do you think the therapy worked? }\end{array}$ \\
\hline \multirow[t]{8}{*}{$\begin{array}{l}\text { What would you say are the top priorities in deciding } \\
\text { for use of CAM therapies during pregnancy and birth? }\end{array}$} & $\begin{array}{l}\text { What were your biggest safety concerns for the CAM method(s) } \\
\text { used by your patients? }\end{array}$ \\
\hline & $\begin{array}{l}\text { Do you think providers should routinely ask patients if they are using } \\
\text { CAM therapies? }\end{array}$ \\
\hline & $\begin{array}{l}\text { If/When a patient asks for information about CAM use - or state that } \\
\text { they are using a particular method, how do you typically respond? }\end{array}$ \\
\hline & $\begin{array}{l}\text { What factors are influential in your decision to recommend for or } \\
\text { against the CAM therapy a patient was considering to use? }\end{array}$ \\
\hline & $\begin{array}{l}\text { What information do you feel is needed to make a decision for or } \\
\text { against use of CAM therapies during pregnancy? }\end{array}$ \\
\hline & $\begin{array}{l}\text { Where do you go for information about a CAM method that a patient } \\
\text { may ask about using during pregnancy and/or birth? }\end{array}$ \\
\hline & Were CAM therapies included in your clinical training? \\
\hline & $\begin{array}{l}\text { Have you had any personal experience using CAM therapies, } \\
\text { particularly in pregnancy and/or birth and how influential has that } \\
\text { been in discussing use of CAM with your patients? }\end{array}$ \\
\hline
\end{tabular}

\section{Broad themes and patterns}

\section{Pregnant respondents}

Four broad themes emerged following discussion with pregnant women. These themes included seeking information from respected sources, belief that a given method will work, seeking support, avoiding those believed to be in opposition to personal beliefs, and a desire for natural processes and non-interference in pregnancy and birth.

Pregnant respondents sought information about CAM therapies from a wide variety of sources, but the importance of obtaining information from a trusted source was clear. Respondents mentioned receiving information from their midwife, co-workers, doula, massage therapist, herbalist, books and online sources, and family members with experience in using the particular method. Pregnant respondents emphasized that some midwives and obstetricians were of no help in providing information nor did they create an environment open to the discussion of use. One woman said "My midwife's practice has not been helpful at all, but I did a lot of my own research on the Internet and talked to my acupuncturist". Another emphasized this same point commenting, "there is not even conversation about alternative ways; you have to find it somewhere else". Another respondent stated that her midwife recommended certain books on CAM therapy use in pregnancy, but did not recommend specific therapies.

Pharmacists were not mentioned as a source that these women would seek out for information and obstetrical physicians were dismissed by the women as sources of information on CAM therapies. One pregnant respondent said "I do not routinely ask them (physicians) but I would not be afraid to ask them." Interestingly, patients mentioned use of the Internet but were unclear on how to evaluate the credibility of information on a given site. One respondent stated that she would trust a site "if it was mentioned in a book or magazine as a good source of information."

Pregnant respondents also seemed to recognize that there was wide variability in knowledge about use of different CAM therapies. As an example, one pregnant woman noted that an herbalist was available through a local health food store but that "she is sometimes lacking information about use during pregnancy." Finally, respondents stated that they had to be responsible for researching how a particular CAM method might work and the safety during pregnancy, but acknowledged that was not always done. One pregnant respondent noted that she used a particular therapy, though she was "very 
Table 2. Respondent characteristics.

\begin{tabular}{|c|c|c|}
\hline \multicolumn{3}{|c|}{ Pregnant women $(n=3)$} \\
\hline Variable & $\mathbf{n}$ & $\%$ \\
\hline \multicolumn{3}{|l|}{ Age (years) } \\
\hline $21-30$ & 1 & 33.3 \\
\hline $31-34$ & 1 & 33.3 \\
\hline $35-40$ & 1 & 33.3 \\
\hline \multicolumn{3}{|l|}{ Marital status } \\
\hline Single & 1 & 33.3 \\
\hline Married & 2 & 66.6 \\
\hline \multicolumn{3}{|l|}{ Race/Ethnicity } \\
\hline Hispanic & 1 & 33.3 \\
\hline White, non-Hispanic & 2 & 66.6 \\
\hline \multicolumn{3}{|l|}{ Religious affiliation } \\
\hline Christian & 1 & 33.3 \\
\hline No religious affiliation & 1 & 33.3 \\
\hline No response & 1 & 33.3 \\
\hline \multicolumn{3}{|l|}{ Occupation } \\
\hline Professional & 2 & 66.6 \\
\hline Technical & 1 & 33.3 \\
\hline \multicolumn{3}{|c|}{ Education (years completed) } \\
\hline Associate's degree & 1 & 33.3 \\
\hline Bachelor's degree & 1 & 33.3 \\
\hline Graduate degree & 1 & 33.3 \\
\hline \multicolumn{3}{|l|}{ Pregnancy provider } \\
\hline Nurse midwife & 3 & 100 \\
\hline Obstetrician & 0 & 0 \\
\hline \multicolumn{3}{|c|}{ Gestational age (current) } \\
\hline 21-37 weeks & 2 & 66.6 \\
\hline 37 weeks & 1 & 33.3 \\
\hline \multicolumn{3}{|c|}{ CAM use in current pregnancy } \\
\hline Yes & 2 & 66.6 \\
\hline No & 1 & 33.3 \\
\hline \multicolumn{3}{|l|}{ CAM use in the past } \\
\hline Yes & 2 & 66.6 \\
\hline No & 1 & 33.3 \\
\hline \multicolumn{3}{|c|}{ Providers $(n=4)$} \\
\hline Variable & $\mathbf{n}$ & $\%$ \\
\hline \multicolumn{3}{|l|}{ Gender } \\
\hline Female & 4 & 100 \\
\hline Male & 0 & 0 \\
\hline \multicolumn{3}{|l|}{ Marital status } \\
\hline Single & 1 & 25 \\
\hline Married & 2 & 50 \\
\hline Divorced & 1 & 25 \\
\hline
\end{tabular}


Table 2. Contd.

\begin{tabular}{lcc}
\hline Race/Ethnicity & 4 & 100 \\
White, non-Hispanic & & \\
Religious affiliation & 3 & 75 \\
Christian & 1 & 25 \\
No religious affiliation & & \\
Employment & 1 & 25 \\
Full-time & 3 & 75 \\
Part-time & & \\
Type practice facility & 1 & 25 \\
Private & 3 & 75 \\
Public & & \\
Obstetrical practice area(s) & 4 & 100 \\
Prenatal & & \\
Intrapartum & 2 & 50 \\
Postpartum & 3 & 75 \\
Years of clinical Obstetrical practice & & \\
$>20$ years & 4 & 100 \\
\hline
\end{tabular}

any given CAM therapy. One patient stated:

I do not know if it is going to happen or not but at my acupuncturist they have little needles that they can put in some pressure points and it can help relieve labor pain. If I go into labor I will stop by and get those little needles, I do not know the name for it, but it is needles that you can have for a few hours, they are taped in you. I think here in the shoulder area, two in the legs, and two in the hands.

The belief that a CAM method would work and was safe was acknowledged by respondents to be an extension of the individual's cultural background and was based on an openness to try alternative therapies and an intuitive sense that a given method was the right thing to use. One pregnant respondent commented, "You know intuitively if it aligns with your belief system." Another added "I can say that maybe my cultural background influences my decision to use alternative therapies. I am not American; I did not grow up here so I did not grow up with the Western medicine in mind. Other cultures are probably more open to these ideas." Family traditions and personal beliefs were further confirmation of the decision to use a CAM method. Still another respondent said her cultural background also influenced her decision to try CAM therapies. "I was not born here either. I do not even think my mother knew what an epidural was until my sister in law had one last year. She is very into doing it all natural, not taking any medicine."

An important corollary to cultural context and an intuitive sense that a method was the correct thing to use during pregnancy was whether or not the method had been used in the past. If the woman had successfully used a given CAM therapy in the past, then she was likely to use it again. One respondent commented:

I had massages throughout pregnancy, with my last pregnancy and with this one I intend to do a massage every week. I did a massage every week in the last month of my previous pregnancy. That is something that I have used with good result, not just like a relaxing kind of massage, more like focused, sternal release to help with breathing. I also do yoga.

Pregnant respondents believed that CAM therapies are natural and should be embraced during pregnancy. Most of the women had used at least one CAM method prior to the pregnancy $A$ related and important aspect was that some of the women felt that obstetrical providers "do not see pregnancy as a normal process, they treat us as patients and not as partners and this pregnancy is a completely natural process." Failure to discuss CAM therapies with patients was seen as a failure to support the personal beliefs of the patient.

Personal beliefs were also seen as an important factor in the decision to use a given CAM therapy in the face of little information about safety and effectiveness during pregnancy. Patients recognized the paucity of information and given such sparse information had to base the decision on personal beliefs. One patient stated that she wanted to try different herbal teas during the pregnancy but when going to varied web sites "they tell us that we 
Table 3. CAM use by pregnant women and nurse midwives in this study.

\begin{tabular}{|c|c|c|c|}
\hline \multicolumn{2}{|r|}{ Pregnant women } & \multicolumn{2}{|c|}{ Nurse midwives } \\
\hline CAM used & Stated indication & CAM used & Other patient CAM inquiries \\
\hline Acidophilus & Gastrointestinal health; vaginitis & Accupressure & Castor oil \\
\hline Acupressure & Pain relief, headaches & Chamomile & Cohosh \\
\hline Acupuncture & Pain relief & Echinacea & Eucalyptus oil \\
\hline Cherry bark syrup & Cough & $\begin{array}{l}\text { Emergen-C (supplement mix: vitamin } \mathrm{C} \\
\text { and B; electrolytes, nutrients, antioxidants) }\end{array}$ & Green tea \\
\hline Chinese balm (vapors) & Upper respiratory infection & Evening primrose oil & Hydrotherapy \\
\hline Chinese herbs & Sustain pregnancy & Ginger & Lavender \\
\hline Citrus essential oils & Nausea & Honey & Lemon Oil \\
\hline Ginger & Nausea & Nasal saline washes & Manipulative therapy (chiropractor) \\
\hline Hydrotherapy & Pain relief & Oatmeal baths & Melatonin \\
\hline Lavender & Relaxation & Red raspberry leaf & Moxibustion \\
\hline Lemon oil & Nausea & & Soy \\
\hline Limes & Nausea & & Vitamin B6 \\
\hline Massage & Overall health, relaxation, well-being & & \\
\hline Moxibustion & Breech presentation & & \\
\hline Red raspberry leaf & Promote cervical ripening; easier labor; less blood loss & & \\
\hline Yoga & Overall health, relaxation, well-being & & \\
\hline
\end{tabular}

Table 4. Pregnant women and nurse midwives' decision-making for CAM use: codes and themes.

\begin{tabular}{|c|c|c|c|}
\hline \multicolumn{2}{|l|}{ Pregnant respondents } & \multicolumn{2}{|c|}{ Nurse midwife respondents } \\
\hline Code & Theme & Code & Theme \\
\hline $\begin{array}{l}\text {-Suggestions for use by those patient respects } \\
\text {-Trying to find credible source for use during pregnancy } \\
\text {-Willing to use a CAM method if recommended by someone } \\
\text { knowledgeable even if patient did not know what it contained or how it } \\
\text { works } \\
\text {-Marketing through social media }\end{array}$ & $\begin{array}{l}\text { Seeking information } \\
\text { from respected } \\
\text { sources }\end{array}$ & $\begin{array}{l}\text {-Safety data lacking } \\
\text {-Lack of authoritative sources } \\
\text {-Lack of skills to evaluate available data } \\
\text {-Conflicting data } \\
\text {-Need for regulation }\end{array}$ & Lack of knowledge \\
\hline
\end{tabular}


Table 4. Contd.

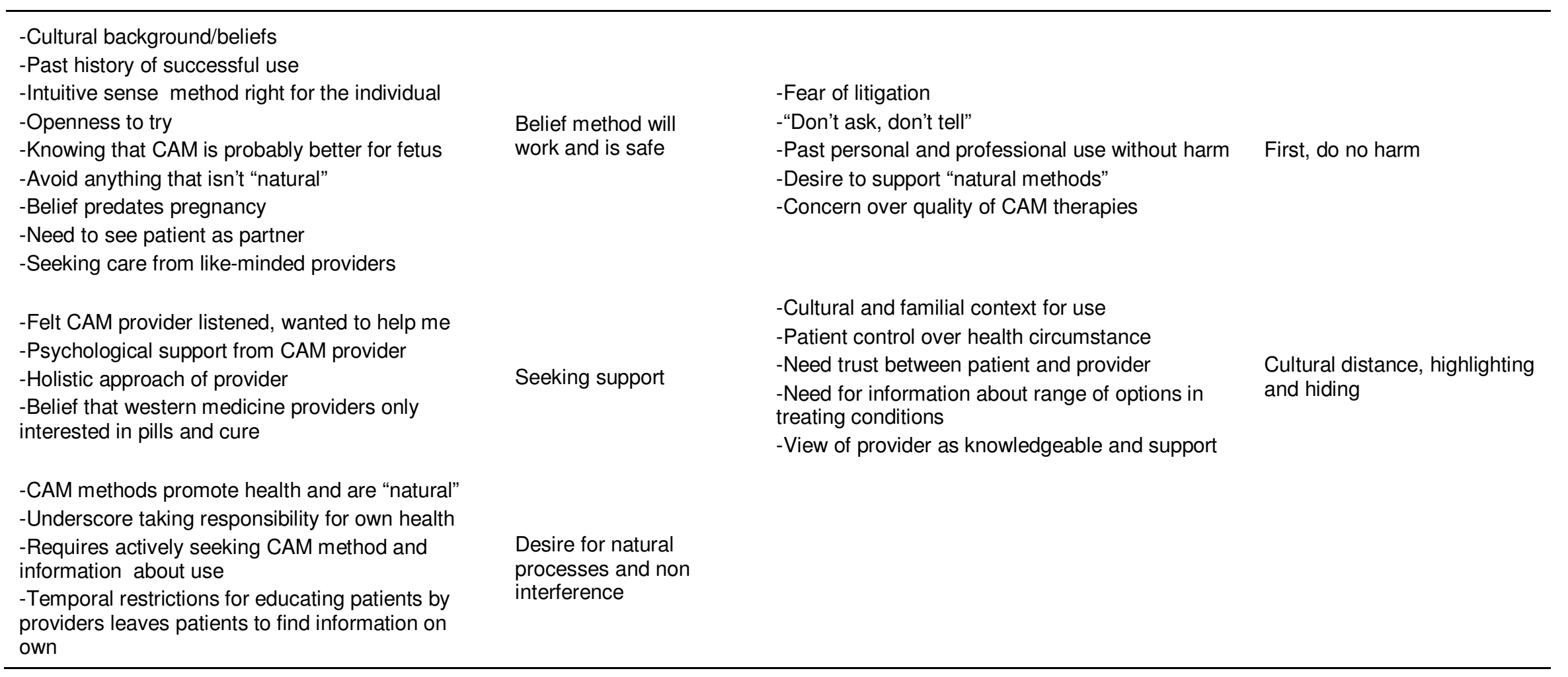

should not use it during pregnancy, but they do not explain what we can do. I think there is a gap there, there is not enough information given to women and we need to be educated, how else can we make these decisions?"

Seeking support from a provider was noted to be of importance in the decision to use a given CAM method. References were made to the importance of the provider listening, wanting to help, and providing psychological support. One respondent remarked "I was very nervous at the beginning, I was very stressed and uncertain -a lot of those things. They [CAM providers] were there for me, and I have never experienced that in a medical office, unfortunately." Respondents also emphasized that traditional obstetrical providers are not experts in CAM therapies and that they do not give holistic care which was considered synonymous with care by a CAM provider Further, lack of discussion about use of CAM therapies was seen as an affirmation that only Western medicine approaches were useful and that other remedies were not even considered. One pregnant woman noted, "The practice I go to;
I think they practice very Western medicine. There is not even conversation about alternative ways; you have to find it somewhere else". Where obstetrical providers were believed to be in opposition to personal beliefs about CAM use, respondents either sought care from another provider who was consistent with their beliefs or did not volunteer that they were using a given CAM therapy.

Desire for natural processes and noninterference in pregnancy and birth reflected respondent belief in the need to take personal 
responsibility for health, promote self-health, and prevent health problems from developing. Doing so engendered the need to educate themselves about CAM methods so that a responsible decision could be made. Use of CAM methods were largely viewed as one means of taking responsibility for health that was not available from traditional, Western medicine health care providers who were viewed as lacking knowledge and too busy to have time to discuss.

All respondents expressed frustration and concern for how difficult it was to get information from the obstetrical provider, because providers were perceived as being too busy to spend time with the patient. One pregnant respondent noted, "Our visits in the office are more for fun. 'Hey how are you doing today? Any complaints? No? Gotta get back to work." This woman added "I would believe that they would take time for you if they had the ability. I just do not know if that is just something that is fostered by having twenty patients in an hour." This woman's concern was echoed by another pregnant respondent who stated:

I expressed the same concern with one of the midwives and she said 'I have 34 patients, I do not have time.' I feel like there is not even time to talk about the normal birth process, they could have provided us with a list of resources, ideas, and books. That is not difficult to do, it does not take time. I feel that if I did not stumble up on a bunch of resources in the library or talked to the right people I would have never gotten to where I should be. I think the problem is, in part, a system [issue].

In addition to too little time to discuss CAM use, respondents believed that there was disinterest on the part of obstetrical providers regarding whether or not they were using CAM therapies. All respondents however, stated they would admit to use of CAM methods if asked.

All respondents felt that CAM methods, in general, promote health, are "natural" and require the responsible individual to actively seek information about use. In addition, a prevalent theme was the desire to support natural processes and to avoid interference with that process. One pregnant respondent noted:

When I was having heartburn or I could not eat, it was suggested that I just take some zantac, that it will make it better and I was like no, I think I would just rather not eat. I just do not want to put anything in my body, and that is not just me in pregnancy, that is me normally.

\section{Nurse midwife providers}

Discussion with obstetrical providers who were all nurse midwives, found three broad themes that were important in decision-making for use of CAM therapies during pregnancy and birth. These themes were lack of knowledge, 'first do no harm,' and cultural distance, highlighting and hiding.

The first theme that was noted was a lack of knowledge. Much of the expressed sentiment by respondents centered on the frustration of no authoritative source(s) for information about the safety, efficacy, and dosing of a given CAM method.

My biggest thing is I want to know if there are known adverse effects. That is why I get a fat book and would look it up if they ask me. I want to be able to say this has been shown to cause problems and advise against. Other than that all I can say is there is no evidence, I do not know, I cannot recommend.

Another respondent echoed this sentiment adding, "Or you say, people have been doing this for centuries but I cannot tell you good or bad." Another noted, "It [use of CAM] is a risk-benefit; it is not black and white."

Additionally, existing data were often conflicted making it difficult to provide a sound recommendation to patients. Nurse midwifery respondents made several comments related to this paucity of CAM information and discomfort in recommending use without stronger evidence. One midwife said:

"[CAM] is not main stream; it is not like we have all been raised with it." She went on to discuss marijuana for nausea and said "I think we all know that weed helps a lot of people... with morning sickness but you cannot say 'Sure it works great!' There is just not much information in the United States".

She went on to say:

It would be nice to be more comfortable. Some of my patients and I am sort of medical model these days will say, 'What can I take for a cold?' And I will say blah, blah, blah these medications and they go 'Well, I do not want to take things while I am pregnant.' It would be nice but we know some alternatives are not nice either, or we cannot prove that they are safe.

I do not have any knowledge - that is the problem. If it looks like it is safe in the literature or wherever I dig something up, then I say you can probably try this. I mean, not that I am sure that it works, but if they want to try it, and they think that it might work

Another midwife said:

"I try to give the patient a variety of options for treatment. Chicken soup for colds...nasal saline washes for congestion, and honey for coughs. So there are a lot of things like that which are incorporated, but in terms of herbal, I have a lot of discomfort because again, the literature is conflicting." 
Information related to use of CAM therapies during pregnancy was of particular concern. One nurse midwife commented, "Most of the natural products and the ones that I have looked up before have information but nothing related to pregnancy."

The need for sound evidence of safety and efficacy for varied CAM therapies was clearly articulated, as well as the need for regulation of products and methods. A respondent commented that the same information is needed about CAM methods "as are available in the prescription drug reference materials-safety, category, dosage". Another respondent noted:

"One, we need the studies, but two we need oversight on the growing and preparation of different herbs and other CAM methods as well as what is the best delivery system."

Greater regulation of CAM products was seen as making the decision easier to recommend for or against use by pregnant women. Such regulation was seen as being most effectively accomplished by a separate government board outside the current regulatory bodies. Regulation, such as that of the German Commission E, was thought to have the potential to offer useful information to both patients and providers.

While there was a clear desire for greater governmental regulation as a means of ensuring product safety and quality, there was some feeling that natural food stores "have quality products" though that was believed to vary widely by store and resources.

...I prefer to send them [pregnant women] to the place that I send them to because I know that at least they have a reputation for quality control in the products that they put out. [They sell] various herbs, but their labels the stuff that they get, they get from companies that have quality control standards.

In the face of absent, little or conflicted information about varied CAM methods, study respondents sometimes sought out the opinion of physician colleagues. One nurse midwife noted, "I was talking to a couple of our physicians about herbs and what they tell patients. Their approach is 'We do not have studies therefore we cannot recommend it. If you want to do your research and you feel like it is safe, go ahead, but I am not recommending it." In general, however, respondents felt that physicians do not know any more [about CAM methods] than they do." Further, respondents felt that pharmacists were not helpful in obtaining knowledge about CAM therapies.

With little empirical evidence, nurse midwifery respondents felt more comfortable recommending use of some CAM therapies if they were available through mainstream sources. For example, herbs that could be obtained at the grocery store (e.g., ginger) were viewed as more likely to be safe than where the product had to be purchased through a specialty store, such as Actea racemosa (black cohosh). One respondent commented, "Essentially we are comfortable recommending things that are foods, even though it is not necessarily any safer. It feels more comfortable to recommend things that are on the grocery shelf."

Nurse midwife respondents also acknowledged the inability to evaluate what information was available about CAM methods and having had little educational preparation about use of CAM therapies. This gap in training created uncertainty of knowledge which nurse midwives attempted to fill through continuing education programs and a search of available resources. One respondent noted "I did not have CAM education in my training program, but I have been taking a few continuing education courses, because it seems like I am lacking something but I am not sure they are helping."

Empirical materials about CAM therapies if, they did exist, were noted to be of greater reliability but were often found to be inaccessible or hard to access, compounding the frustration and anxiety for recommending for or against use of a method. One nurse midwife expressed this difficulty in accessing materials when she stated, "there is a natural comprehensive database that is really good, but it is expensive and I have not joined it. But I would trust that site, if I were inclined to pay for it. It has stuff that I would use." Another respondent also agreed with difficulty accessing information.

I used to try Google or WebMD. I tried to call pharm but nobody answers. I tried UptoDate, Lexicon sometimes, and that natural medicine database if I can get into that. I can get into the other two from Epic but not natural medicines. I could not get anything over here.

A second theme was captured with the oft-used phrase, first, do no harm. Nurse midwifery participants expressed worry about recommending or endorsing many available CAM therapies. Concern over potential patient harm was coupled with a fear of litigation should a given method have harmful effects following nurse midwifery recommendation.

I do not think there is a standard source. I think so many of us have different experiences. Castor oil, yeah there is a great study at the birth center, in the '80s when they are to be transferred out because they have been trying for too long and they castor oil everybody and it seemed to work. But then another midwife told me about the meconium study, so what do you think? It is hard, people like to sue.

The concern over potential litigation, the lack of information about safety, and the perception of widespread use of CAM therapies fostered a desire to put blinders on about use. One nurse midwife remarked:

"I do not want to know about use. I do not think there is any stigma against herbal treatment or complementary therapies or anything, like there was 20 years ago." 
Fear of litigation caused the nurse midwives to consider the need to document CAM use in the patient record or to avoid mention altogether.

I usually do not document it [CAM use] unless they are really adamant and I have a concern. I cannot document every conversation I have; I have been documenting all night.

I do document sometimes. I get patients who have already seen an herbalist or an acupuncturist. They tell me that they are going there and I usually try to write it down because a lot of times it is like 10 or 12 things and they do not even know what they are on. If they know what they are on, if it is simple I will write it down. If it is not, I will just write something about it, like 'seeing acupuncturist'.

Me too, l'll do that, and the only other thing is advise against. You are worried. I would definitely document 'advised against blue cohosh' kind of thing.

When queried about what factors actually influence the decision to recommend for or against use of a given CAM method, respondents were cautious and favored avoiding use of any CAM method or traditional medications. One nurse midwife remarked:

I basically do not recommend and discourage people from using any kinds of herbs or medicines in pregnancy, prescription, over the counter, whatever. That would be my recommendation; do not put anything in the body that might have an effect on the baby.

Experience was also a factor in the decision to use a CAM method. Where a given method had been used by the provider herself without adverse outcome, the respondent was more likely to feel comfortable endorsing use by pregnant women. Even if the CAM therapy did not have the desired outcome, respondents were comfortable recommending use if the method was viewed as having done no harm. One nurse midwife remarked "I brought my daughter to a chiropractor for headaches and it did not do any good, I think it did negative. Recommend chiropractors to pregnant women with back pain." And another nurse midwife followed up stating, "So you can try it and if it works great, if it does not you have lost anything."

The third theme that was noted was cultural distance, highlighting and hiding which reflected the cultural and family context for use, patient control in the decision to use CAM, the need for information, trust relationship between patient and provider, and provider as knowledgeable and supportive.

Respondents recognized culture and family as an important context in the decision to consider use of CAM therapies for both the pregnant woman and for the nurse midwife. One nurse midwife remarked:
I think as care providers we have our own cultural influences also. Our recommendation comes from a comfort level, mine does anyway. Where does that comfort level come from? Who is using it? Other people are using it... experience with it. I would like to think it is all evidence based but...

Recommending use of CAM was considered in the context of the patient's cultural background. For example, one respondent was comfortable recommending use of select herbs where there was a clear cultural and family tradition. She noted, "I am comfortable saying sure, [use it], particularly with my Hispanic patients, I will tell them take the "manzanilla" (chamomile tea), because they know that, they drink that all the time, it is part of their [culture]."

Nurse midwives believed that the pregnant woman's family and friends were an important influence in patient's making the decision to use CAM therapies and was a factor considered by the nurse midwife in recommending use. It was noted that "women really listen to their family and friends more than their providers" when it comes to CAM use. A corollary to cultural and family influences for use was belief in the placebo effect noting that "the psychological belief that it is going to work is probably a bigger player than the physiologic response to it."

Nurse midwives believed that patients should be routinely asked about CAM use in pregnancy, but admitted that they do not regularly do so. One respondent noted that she did not ask about use every time a pregnant woman was seen but did do so at the initial intake and history. At other health care visits respondents noted that discussion about CAM use was pretty hit-and-miss with one respondent stating that CAM use may "sometimes come up and sometimes it will not." Finally, a more disturbing realization was that many pregnant women were not forthcoming about use of varied CAM methods which respondents interpreted as a lack of trust in the nurse midwife.

I have clients that do not want to be that forthcoming of what they are taking. They do not want me to tell them not to, or they do not want to share it, they do not trust me. I feel like I am laying it on the line, I expect you to as well. We can work together and find a middle ground. Definitely have people that at the very end they say, I have been taking this all along, or I took castor oil for the last three nights.

If the patient disclosed that they were using a CAM method, respondents tried to ask for details about what was actually being used and how it was used. Efforts were then made to provide neutral support for use, telling the patient "something general [like] 'it looks okay but use it with caution'," as well as provide information about a range of options for treatment. Where the nurse midwife was unable to access scientific evidence about the therapy's safety and effectiveness, referral was made to 
someone viewed to be more knowledgeable about CAM.

[If] there is no evidence I cannot recommend. I advise [patients] to go on the web, find all the things, and there are some people you can talk to.

My [use of] complementary things are more, I think when you are giving an advice about a discomfort that you need to give not just pharmacologic responses but alternative things that they can do to help with their symptoms.

I have sent them over to [name of store] and have them talk to the people over there. I do not say that they are correct but that they know more than I do.

There was a general belief by respondents that pregnant women who desired use of CAM methods were more likely to seek care from a nurse midwife with the mistaken impression that nurse midwives were knowledgeable and supportive of the use of CAM therapies. One nurse midwife commented:

In the private clinic they [pregnant women] came to us because they thought that one, we [nurse midwives] would be more knowledgeable and two, more supportive. Wrong on both counts!

Table 4 summarizes the codes and themes across both respondent groups.

\section{DISCUSSION}

This study was limited by the lack of a variety of obstetrical providers, though efforts were made to recruit obstetricians and family practice physicians. The focus groups were also limited in size and would likely have benefited from pregnant women and providers with greater diversity. The small sample size may have resulted in a failure to discover important factors in the decision to use CAM by pregnant women and nurse midwives. Focus groups are typically composed of 5 to 10 participants, but small groups of four or five afford more opportunity for discussion by individual group members, though can result in a smaller number of total ideas (Krueger and Casey, 2009).

There were several key findings which were useful in examining how both pregnant women and nurse midwifery providers make the decision to use CAM therapies. First, and not surprising, a wide variety of methods were used by pregnant women who viewed use as safe, effective, more natural and likely better for the pregnancy despite a paucity of information. Similar findings have been found on examination of CAM use during pregnancy (Guittier et al., 2012). Use during pregnancy was reported as an extension of past CAM behavior.

Second, both pregnant women and nurse midwives expressed a clear need for additional knowledge related to the safety and efficacy of CAM therapies. Frustration in accessing trustworthy information was evident for both groups. Where empirical data was sparse or absent, other sources of information were sought such as Internet websites and books, and advice from natural health food stores. These findings are worrisome as neither the Internet or health food store sources have been found to be solid sources of reliable information. A recent study examined websites providing lists of prescription medications reported to be safe during pregnancy; inconsistent and inaccurate information about those drugs was found (Peters et al., 2013). With even less empirical data related to CAM therapies it is likely that Internet information is largely inaccurate as well. Given how commonly pregnant women and obstetrical providers appear to use the Internet for CAM information, rigorous examination of existing information is needed. Examination of advice from natural health food stores and pharmacies about use of CAM products during and friends" more than their providers" when it comes to pregnancy has been found to be incorrect and potentially hazardous, suggesting the need for regulatory reform of CAM products and those who sell them (Jefferies et al. 2012).

Pregnant respondents also reported confusion, regarding reliability of the information they found and expressed uncertainty in how to determine the accuracy of information they did locate. In a similar vein, nurse midwifery respondents admitted to lacking skills to confidently evaluate the available evidence. This finding has been noted in other research (Hastings-Tolsma and Terada, 2009; Hirschkorn and Bourgeault, 2007). Providers should know how to access and evaluate information to allow for accurate counseling of patients (Low Dog, 2009). Given the large numbers of pregnant women who purportedly use such products and the potential for adverse outcome, consideration should be given to development of a widely accessible compendium of information that specifically addresses maternal-fetal risks and benefits with CAM use.

It is also important to note that nurse midwives in this study perceived that information about CAM in nurse midwifery educational programs was lacking and attempted to compensate for limited knowledge by attending continuing education programs and other selfstudy. Consistent with findings from other research (Wiebelitz et al., 2009), respondents questioned the value of self-study as a useful means for learning about CAM. Failure to mainstream CAM information into provider educational programs has been previously noted (Hastings-Tolsma and Terada, 2009; Low Dog, 2009) with suggestion that all midwives receive basic CAM education (Hall et al., 2013). It is unknown to what extent nurse midwifery educational programs include CAM information and survey of midwifery educational programs would be valuable addition to the literature. Creative solutions are needed to mainstream knowledge about CAM at a time when large numbers of pregnant 
women, among others, are using such therapies.

In the face of frustration and gaps in knowledge, providers were cautiously neutral in recommending use and admitted readily referring pregnant women to other more knowledgeable CAM providers, consistent with other research where a large percentage of nurse midwives surveyed report referrals (Hastings-Tolsma and Terada, 2009; Adams et al., 2011). Such referrals may underscore a fundamental belief in CAM as more natural and an effort to promote normal pregnancy and birth. Given this propensity, it would be useful to consider interprofessional education of nurse midwives and other qualified CAM practitioners as has been suggested by Steel and Adams (2012).

Third, and contrary to previous research (Adams et al., 2009; Steel et al., 2012; Westfall, 2003), pregnant respondents did not view obstetrical providers as a source of information about CAM therapies. In fact, pregnant respondents felt that providers were seen as a reflection ofdisregard for the normal physiologic processes of pregnancy and birth. It has been suggested that pregnant women turn to CAM use because of a desire to achieve normal birth (Mitchell, 2013), and because of coventional medicines disregard for a holistic approach and the need for more personal control (Low Dog, 2009). These perceptions by pregnant women interested in CAM use has been reported elsewhere (Steel et al., 2012; Hall et al., 2011).

The fact that pregnant respondents did not see their obstetrical provider as a source of information about CAM use may reflect differences in the role of midwives across the globe or, more likely, reflect the medically-oriented practice environment of the obstetrical providers the pregnant women saw for care. In addition, provider concern for adverse outcome and potential litigation were influential in the decision to recommend use. While expressing a desire to support the use of more natural CAM therapies, safety concerns limited recommendation for use. Establishing a midwifery model of care as practice standard for pregnancy and birth instead of the dominant illness oriented medical model, would likely address these concerns for both nurse midwives and pregnant women.

The fourth finding is related to open communication and dialogue between pregnant women and obstetrical providers. Short clinical appointment times were raised as a major factor in limited provider-patient dialogue. While nurse midwives indicated asking pregnant women about use of CAM methods at the initial intake visit, inquiry beyond that was infrequent if at all. This finding contradicts other literature where the majority of nurse midwives reported regularly asking patient about CAM use (Hastings-Tolsma and Terada, 2009). It was also disconcerting that nurse midwives believed pregnant women were not always forthcoming in disclosing use of CAM, though prior study found that more than $75 \%$ of pregnant CAM users did not tell their obstetrical provider (Holst et al., 2009). Similarly, approximately one-third of pregnant women who consult CAM therapists do not inform their obstetrical provider (Eisenberg et al., 2001). Reluctance for disclosure has been found to be particularly true for minority populations (Chao et al., 2008) where CAM use is believed to be substantial (Brown et al., 2007; Lee et al., 2010; Mehta et al., 2007). Given the potential for fetal harm, providers need to develop a practice environment that encourages open dialogue with pregnant women and ready disclosure about CAM use (Hall et al., 2011). All pregnant women should be routinely queried about use of CAM (Hall et al., 2012, 2011; Holst et al., 2009) and patient desire for CAM use considered as part of deliberations in clinical decision-making within varied systems (Hall et al., 2012).

\section{Conclusions}

In summary, pregnant women in this study tended to view CAM therapies as safe and natural, even herbs which were not seen as "medicine." While nurse midwives wanted to support use, a lack of empirical data and concern for potential litigation made respondents reticent to give more than tacit approval for use. Both pregnant women and nurse midwives attempted to locate credible CAM information as a guide for use but had difficulty accessing authoritative sources and in determining the reliability of materials that were available. Cultural beliefs, personal experience and recommendation from trusted sources such as family and friends were of greatest weight in making the decision for CAM use.

Numerous studies suggest substantial CAM use during pregnancy across the globe (Hastings-Tolsma and Terada, 2009; Guittier et al., 2012; Holst et al., 2009, 2011; Eisenberg et al., 2001). Given the paucity of clinical evidence for the safety and efficacy during pregnancy of most CAM therapies (Holst et al., 2011), innovative strategies are needed in the development of decision-making methods that can fill the knowledge gap regarding effectiveness of such methods. Such strategies should include how pregnant women and obstetrical providers reconcile differences in the decision to use CAM therapies during the crucial developmental period of pregnancy.

\section{ACKNOWLEDGEMENT}

The authors would like to thank Patti McHardy, MS, CNM for her support in the conduct of this research. Without her assistance, this study would not have been possible.

\section{REFERENCES}

Adams J, Lui CW, Sibbritt D, Broom A, Wardle J, Homer C, Beck S (2009). Women's Use of Complementary and Alternative Medicine During Pregnancy: A Critical Review of the Literature. Birth $36(3): 237-245$ 
Adams J, Lui CW, Sibbritt D, Broom A, Wardle J, Homer C (2011). Attitudes and referral practices of maternity care professionals with regard to complementary and alternative medicine: an integrative review. J. Adv. Nurs. 67(3):472-483.

Barnes PM, Bloom B, Nahin RL (2007). Complementary and Alternative Medicine Use Among Adults and Children: United States. Available at: http://nccam.nih.gov/news/2008/nhsr12.pdf

Blanchard MA, Rose LE, Taylor J, McEntee MA, Latchaw LL (1999). Using a Focus Group to Design a Diabetes Education Program for an African American Population. Diabetes Educ. 25(6):917-924.

Brown CM, Barner JC, Richards KM, Bohman TM (2007). Patterns of Complementary and Alternative Medicine Use in African Americans. J. Altern. Complement. Med. 13(7):751-758.

Caspi O, Koithan M, Criddle MW (2004). Alternative Medicine or "Alternative" Patients: A Qualitative Study of Patient-Oriented Decision-Making Processes with Respect to Complementary and Alternative Medicine. Med. Decis. Making 24(1):64-79.

Chao MT, Wade C, Kronenberg F (2008). Disclosure of Complementary and Alternative Medicine to Conventional Medical Providers: Variation by Race/Ethnicity and Type of CAM. J. Natl. Med. Assoc. 100(11):1341-1349.

Claxton K (1999). The Irrelevance of Inference: A Decision-Making Approach to the Stochastic Evaluation of Health Care Technologies. J. Health Econ. 18(3):341-364.

Eisenberg DM, Kessler RC, Van Rompay MI, Kaptchuk TJ, Wilkey SA, Appel S, Davis RB (2001). Perceptions about Complementary Therapies Relative to Conventional Therapies Among Adults Who Use Both: Results From a National Survey. Ann. Intern. Med. 135(5):344-351

Furlow ML, Patel DA, Sen A, Liu JR (2008). Physician and Patient Attitudes Towards Complementary and Alternative Medicine in Obstetrics and Gynecology. BMC Complement. Altern. Med. 8:35.

Gibson PS, Powrie R, Star J (2001). Herbal and Alternative Medicine Use During Pregnancy: A Cross-Sectional Survey. Obstet. Gynecol. 97(4 (suppl 1)):S44-S45.

Guittier MJ, Pichon M, Irion O, Guillemin F, Boulvain M (2012). Recourse to Alternative Medicine During Pregnancy: Motivations of Women and Impact of Research Findings. J. Altern. Complement. Med. 18(12):1147-1153.

Halcomb EJ, Gholizadeh L, Digiacomo M, Phillips J, Davidson PM (2007). Literature review: considerations in undertaking focus group research with culturally and linguistically diverse groups. J. Clin. Nurs. 16: 1000-1011.

Hall HG, Griffiths DL, McKenna LG (2011). The Use of Complementary and Alternative Medicine by Pregnant Women: A Literature Review. Midwifery 27(6):817-824.

Hall HG, Griffiths DL, McKenna LG (2012). Complementary and Alternative Medicine in Midwifery Practice: Managing the Conflicts. Complement. Ther. Clin. Pract. 18(4):246-251.

Hall HG, McKenna LG, Griffiths DL (2013). From Alternative, to Complementary to Integrative Medicine: Supporting Australian Midwives in an Increasingly Pluralistic Maternity Environment. Women Birth 26(2):e90-93.

Hastings-Tolsma M, Terada M (2009). Complementary Medicine Use by Nurse Midwives in the U.S. Complement. Ther. Clin. Pract. 15(4):212-219.

Hepner DL, Harnett M, Segal S, Camann W, Bader AM, Tsen LC (2002). Herbal Medicine Use in Parturients. Anesth. Analg. 94(3):690-693.

Hirschkorn KA, Bourgeault IL (2007). Actions Speak Louder than Words: Mainstream Health Providers' Definitions and Behaviour Regarding Complementary and Alternative Medicine. Complement. Ther. Clin. Pract. 13(1):29-37.

Holst L, Wright D, Haavik S, Nordeng H (2009). The Use and the User of Herbal Remedies during Pregnancy. J. Altern. Complement. Med .15(7):787-792.

Holst L, Wright D, Haavik S, Nordeng $H$ (2011). Safety and Efficacy of Herbal Remedies in Obstetrics-Review and Clinical Implications. Midwifery 27(1):80-86.
Institute of Medicine [IOM] Committee on the Use of Complementary and Alternative Medicine by the American Public (2005) Complementary and Alternative Medicine in the United States. National Academies Press, Washington, DC

Jefferies S, Healy B, Weatherall M, Beasley R, Shirtcliffe P (2012). What Risks do Women Face When Seeking Advice During Pregnancy from Pharmacies and Natural Health Retailers? N. Z. Med. J. 125(1367):61-69.

Krueger R, Casey MA ( 2009). Focus groups: A Practical Guide for Applied Research. 4th ed., Thousand Oaks, Sage Publications, CA.

Lee JH, Goldstein MS, Brown ER, Ballard-Barbash R (2010). How does acculturation affect the use of complementary and alternative medicine providers among Mexican- and Asian-Americans? J. Immigr. Minor. Health 12(3):302-309.

Low Dog T (2009). The Use of Botanicals During Pregnancy and Lactation. Altern. Ther. Health Med. 15(1):54-58.

Mehta DH, Phillips RS, Davis RB, McCarthy EP (2007). Use of Complementary and Alternative Therapies by Asian Americans. Results from the National Health Interview Survey. J. Gen. Intern. Med. 22(6):762-767.

Mitchell M (2013). Women's Use of Complementary and Alternative Medicine in Pregnancy: A Journey to Normal Birth. Br. J. Midwifery 21(2):100-106.

National Center for Complementary and Alternative Medicine [NCCAM] (2012). What is complementary and alternative medicine? Available at: http://nccam.nih.gov/health/whatiscam

Pan SY, Gao SH, Zhou SF, Tang MK, Yu ZL, Ko KMK (2012). New Perspectives on Complementary and Alternative Medicine: An Overview and Alternative Therapy. Altern. Ther. Health Med. 18(4):20-36.

Peters SL, Lind JN, Humphrey JR, Friedman JM, Honein MA, Tassinari MS, Moore CA, Mathis LL, Broussard CS (2013). Safe Lists for Medications in Pregnancy: Inadequate Evidence Base and Inconsistent Guidance from Web-Based Information, 2011. Pharmacoepidemiol. Drug Saf. 22(3):324-328.

Refuerzo JS, Blackwell SC, Sokol RJ, Lajeunesse L, Firchau K, Kruger M, Sorokin Y (2005). Use of Over-the-Counter Medications and Herbal Remedies in Pregnancy. Am. J. Perinatol. 22(6):321-324.

Steel A, Adams J (2012). Developing Midwifery and Complementary Medicine Collaboration: The Potential of Interprofessional Education? Complement. Ther. Clin. Pract. 18(4):261-264.

Steel A, Adams J, Sibbritt D, Broom A, Gallois C, Frawley J (2012). Utilisation of Complementary and Alternative Medicine (CAM) Practitioners within Maternity Care Provision: Results from a Nationally Representative Cohort Study of 1,835 Pregnant Women. BMC Pregnancy Childbirth 12:146.

Tsui B, Dennehy CE, Tsourounis C (2001). A Survey of Dietary Supplement Use During Pregnancy at an Academic Medical Center. Am. J. Obstet. Gynecol. 185(2):433-437.

Upchurch DM, Chyu L, Greendale GA, Utts J, Bair YA, Zhang G, Gold EB (2007). Complementary and Alternative Medicine Use Among American Women. Findings from The National Health Interview Survey, 2002. J. Womens Health 16(1):102-113.

Ventegodt S, Orr G, Merrick J (2011). The Need for Evidence-Based, Non-Drug Medicine. Int. J. Adolesc. Med. Health 24(2):113-119.

Vincent D, Clark L, Zimmer LM, Sanchez J (2006). Using Focus Groups to Develop a Culturally Competent Diabetes Self-Management Program for Mexican Americans. Diabetes Educ. 32(1):89-97.

Westfall RE (2003). Herbal Healing in Pregnancy: Women's Experiences. J. Herb Pharmacother. 3(4):17-39.

World Health Organization [WHO] (2008). Traditional Medicine Fact Sheet. Available at: http://www.who.int/mediacentre/factsheets/fs134/en/

Wiebelitz KR, Goecke TW, Brach J, Beer A-M (2009). Use of Complementary and Alternative Medicine in Obstetrics. Br. J. Midwifery 17(3):169-175. 